\title{
Treading on a Foreign Land: A Multiple Case Study of Chinese International Students' Academic Acculturation Experiences
}

\author{
Deyu (Cindy) Xing \\ Queen's University, Ontario, Canada \\ Benjamin Bolden \\ Queen's University, Ontario, Canada
}

\begin{abstract}
This article reports a multiple case study to explore the lived academic acculturation experiences of four Chinese international students with limited oral English capacity and how they describe the relationship between low oral English proficiency and academic acculturation. Self-Determination Theory was utilized as the theoretical framework to inform data collection and analysis. Findings indicated all four Chinese students experienced significant psychological stress during their academic acculturation as a direct result of their limited spoken English capacity, which negatively impacted their sense of competence, autonomy and particularly relatedness. Emotional pain, involuntary isolation, helplessness, and regret emerged as the salient themes from the cross-case analysis. Implications for various stakeholders are discussed.
\end{abstract}

Keywords: Self-determination; international students; academic acculturation; Chinese students.

\section{Introduction}

Situated within an increasing trend of globalization and internationalization, it is common practice for students from all over the world to seek post-secondary studies overseas and for universities to actively recruit international students. The potential benefits for international students are significant, including more diverse education opportunities, rich personal experiences, and enhanced possibilities for post-graduation employment (Elliot, Reid, \& Baumfield, 2016). There are also corresponding benefits for universities; international students bring campus diversity, economic gains, and job opportunities (Zhang \& Beck, 2014). However, the benefits can be accompanied by significant challenges.

In an extensive review of the literature addressing the academic acculturation experiences of international students, Smith and Khawaja (2011) revealed that common acculturative stressors encountered by international students include language proficiency, discrimination, educational and sociocultural differences, and practical stressors. An earlier review by Chen (1999), focusing on international students enrolled in postsecondary studies in Canada and the United States, indicated that among all the common acculturative stressors international students encountered, language proficiency was salient, because it interacted with other stressors in both academic and non-academic settings. Students who have inadequate language proficiency are vulnerable during their academic acculturation because language difficulty causes stress and anxiety, which pose psychological obstacles (Aubrey, 1991). In fact, many of the transition challenges that international students experience while

This work is licensed under a Creative Commons Attribution 4.0 International Licence. As an open access journal, articles are free to use with proper attribution. ISSN: 2205-0795 
acculturating into a foreign academic setting can be linked to low English language proficiency (Chen, 1999; Sawir, Marginson, Forbes-Mewett, Nyland, \& Ramia, 2012), and more specifically to low English oral language proficiency due to its significant impact on students' engagements in both academic and social activities (Rosenthal, Russell, \& Thomson, 2006).

As a preliminary step towards improving the transitional situations international students with low English oral language proficiency face, and towards maximizing the potential of their international post secondary study, this research sought to understand the academic acculturation experiences of international students with low oral English proficiency, and the relationship between their low oral English proficiency and psychological well-being.

\section{Theoretical Framework}

The design of the study was informed by theoretical understandings of academic acculturation and its relationship with international students' English language proficiency, and by Self-Determination Theory (Deci \& Ryan, 2000).

\section{Academic Acculturation}

Initially, the term "acculturation" was used to refer to the process immigrants go through when settling in a new country (Smith \& Khawaja, 2011). Several models have been developed to describe the acculturation process, with differing emphases on the various factors involved. The models share in common the conceptualization of acculturation as a psychological adaptation process (Smith \& Khawaja, 2011). For the purpose of this research, we conceptualize international students' academic acculturation as a dynamic psychological adaptation process (Berry, 1997) involving a complex and idiosyncratic interplay between academic and non-academic experiences (Cheng \& Fox, 2008) impacted by language proficiency (Chen, 1999).

\section{Self-Determination Theory}

Evolved from a humanistic perspective, Self-Determination Theory (SDT) is a comprehensive macro-theory that is often utilized by researchers to understand human behavior (Teixeira, Carraca, Markland, Silva, \& Ryan, 2012), and is centered on the psychological health of individuals (Teixeira et al., 2012). SDT has been supported and extended by numerous empirical studies, making it a powerful framework for understanding human experience (Deci \& Ryan, 2002). According to SDT, all individuals require the satisfaction of three basic psychological needs to achieve personal wellbeing: autonomy, competence, and relatedness (Deci \& Ryan, 2000). Autonomy concerns the feeling that one's behavior is choiceful and self-determined (de Charms, 1968); competence refers to feeling competent and confident in one's behaviour (White, 1959); and relatedness emphasizes the sense of belonging and feeling personally close to others (Deci \& Ryan, 2000). All individuals require satisfaction of these three psychological needs to function in a healthy manner (Deci \& Ryan, 2000).

While current literature on international students' academic acculturation provides suggestions such as providing social support and language learning to better support international students' success, the literature lacks a comprehensive theoretical framework to explain international students' academic acculturation in higher education (Cho, 2017). Given that academic acculturation is viewed as a dynamic psychological adaptation process (Berry, 1997), and that SDT is concerned with psychological well-being, SDT can serve as a valuable theoretical framework to conceptualize the wellbeing of post-secondary international students and point to comprehensive recommendations. As such, we chose SDT as the lens to guide our literature review, study design and data analysis, and to illuminate our understanding of the complex psychological processes university international students experience during their academic acculturation.

\section{Reviewing the Literature: Intersections of Oral Language Proficiency, Academic Acculturation, and Self- Determination Theory}

Among the four skills of language proficiency (listening, speaking, reading, and writing), speaking is particularly important for international students' academic acculturation. The lack of ability to communicate orally in English with native speakers in a new culture hinders the satisfaction of the three basic human psychological needs proposed by SDT: autonomy, competence, and relatedness (Deci \& Ryan, 2000). 
With regard to the need for autonomy, oral English proficiency could influence international students' ability to self-determine behavioural choices in a variety of settings. In academic settings, international students with low oral English proficiency may feel constrained when making course selection decisions and during academic communication with professors and classmates (Zhang \& Beck, 2014). In social settings, students with low oral English proficiency often feel they must withdraw from activities involving oral communication (Yi, 2004). A lack of oral language proficiency narrows international students' behavioural choices, therefore is likely to undermine the satisfaction of international students' need for autonomy.

Oral English proficiency is also linked to international students' sense of competence. Talking to native speakers is a prime factor in international students' perceived communication competence (Zimmermann, 1995), while frequent intercultural contact based on oral communication enhances international students' English language self-confidence (Yang, Noels, \& Saumure, 2006). Students who effectively communicate orally tend to perceive themselves as more competent and, therefore, feel more confident during their acculturation process than students who have inadequate oral English capacity (Rosenthal, Russell, \& Thomson, 2006).

Studies also demonstrate that oral communicative competence is closely connected to the satisfaction of international students' need for relatedness. The inability to speak the host language fluently is a primary inhibiter for international students in developing intercultural friendships (Hayes \& Lin, 1994). International students who can communicate fluently in oral English have a higher sense of connectedness to English-speaking surroundings when compared with other international students with limited oral English capacity (Rosenthal et al., 2006). In particular, Chinese international students are more likely to experience acculturative psychological stress due to their generally lower oral English capacity (in relation to other international students) (Chen, Liu, Zhao, \& Yeung, 2015; Ippolito, 2007). Given the rising number of Chinese international students worldwide and the often-reported harsh academic acculturation they experience, there exists an ongoing need to further understand the academic acculturation processes of Chinese international students (Meng, Zhu, \& Cao, 2018).

Accordingly, the purpose of this study was to understand the academic acculturation experiences of Chinese international students with low oral English proficiency who were studying at a mid-sized Canadian university. Two research questions guided the research: (1) What are the academic acculturation experiences of four Chinese international students with low oral English proficiency? (2) How do these students describe the impact of their low oral English proficiency had on their academic acculturation?

\section{Methods}

In alignment with the purpose and research questions, this study was guided by a multiple case study design (Yin, 2003). Four different individual cases were examined to understand the academic acculturation experiences of Chinese international students with low oral English proficiency: Kandy, Selina, Nick, and Lisa, different from each other with respect to disciplines and duration of academic acculturation, were purposefully chosen from a broader pool of participants to enable the in-depth exploration of the uniqueness of each case while additionally contrasting similarities and differences through cross-case analysis (Stake, 1995). A multiple case study approach enables researchers to explore "multiple bounded systems (cases) over time, through detailed, in-depth data collection involving multiple sources of information" (Creswell, 2007, p. 73) and to report individual case descriptions and themes (Stake, 1995). As such, we identified multiple case study as an effective method for developing understanding of the academic acculturation experiences of Chinese international students with low oral English proficiency.

\section{Case Selection}

We selected a mid-sized Canadian university where English is the medium of instruction to serve as the context of our study. We required that students were Chinese and were attending university classes. We also used students' admission "Test of English as a Foreign Language" (TOEFL) or "International English Language Testing System” (IELTS) scores as a sampling criterion. If their spoken English scores were at or below the minimum requirement for admission into the university's undergraduate program, the students were considered low in oral English proficiency and given consideration for participation. Other inclusion criteria included enrollment in different programs at the university and different lengths of study in Canada. Because the study required in-depth exploration of Chinese international students' academic acculturation experiences, we decided to carry out multiple data collection sessions with a small number of cases, following Creswell's (2007) methodological 
recommendation of a maximum of four or five cases. In total, seven students responded to our recruitment call. Three were purposefully excluded as they did not meet the inclusion criterion of low oral English proficiency; their TOEFL speaking scores fell above the minimum requirement for their university admission. The remaining four were invited to participate in this study. We stopped further recruitment after selecting four eligible participants, following Creswell's (2007) methodological recommendation of a maximum of four or five cases.

\section{Data Collection}

\section{Semi-structured interviews}

The first author, who is proficient in both Chinese and English, conducted two one-on-one interviews with each participant. We used a pre-determined interview protocol to help elicit directly relevant data to answer the research questions (Leins, Fisher, Pludwinski, Rivard, \& Robertson, 2014), but kept to a semi-structured interview format because it was flexible for capturing voices and experiences (Rabionet, 2011). Each interview began with greetings and an explanation of purpose of the study and the procedures of the interview. Then the participants were asked questions on their overall academic acculturation experiences which included: 1) Can you tell me about your life studying here in general? 2) Can you tell me one of your happiest memories studying in Canada? 3) Can you tell me one of your most frustrating experiences studying in Canada? Next, the participants were asked questions on their academic acculturation experiences specifically related to oral English communication which included: 1) Can you share your oral communication experiences with other students, instructors, and English-speakers outside of school? 2) Can you share your experiences where you found oral English communication difficult studying in Canada? 3) Can you share your experiences where you found oral English communication easy studying here? Lastly, the participants were asked the question related to their chosen artifact: Why did you choose/create this piece for the representation of your acculturation experiences? Probing questions were asked based on participants' answers throughout the interview. One followup interview was also conducted with all four participants after the preliminary analysis of initial interviews to clarify themes or questions that emerged from the data.

All interviews, ranging from 60 to 120 minutes, were conducted in person in Chinese, as the participants were low in oral English proficiency and it was necessary to use the language that they felt most comfortable with and proficient in to describe the richness of their academic acculturation experiences. All interviews were audio-recorded and later transcribed (in Chinese) by the first author. Then the Chinese transcription was sent to the participant to verify that it captured what the participant intended to communicate before translation into English by the first author for data analysis.

\section{Artistic artifacts}

To open up participants' expression of richer answers (Bagnoli, 2009), and to serve as an additional data source to understand the studied phenomenon, we incorporated artistic representations of participants' academic acculturation experiences during the interviews. Prior to the first interview, participants were asked to choose or create a piece or multiple pieces of art to represent some aspect or aspects of their academic acculturation experiences. We encouraged participants to choose an art form with which they felt comfortable (e.g., poetry, song writing, painting). Then, during the interview, we asked the participants to explain why and how the art works they chose or created represented their experiences, to ensure that our interpretation of the art works they brought was responsive to their own meanings and associations. The art works were collected as part of the data.

\section{Reflexive journal and field notes}

The first author kept a reflexive journal to record internal researcher reflections, including assumptions, reactions, and thoughts during the data collection and analysis process, which made the research process visible and provided an additional source of information and triangulation (Ortlipp, 2008). In addition, field notes were taken by the first author immediately after the interviews to record observations, initial thoughts and feelings, when "the situation was still fresh" (Patton, 2002, p. 302) to contribute additional data and help provide a richer description of the participant (Patton, 2002). 


\section{Data Analysis}

Cross-case synthesis was used for analysis (Creswell, 2007; Stake, 1995). As recommended by Stake (1995), the data analysis began with studying each case for its description and themes in a multiple case study design. This process involved (a) organizing each individual case data into a descriptive narrative of the participant's academic acculturation experiences; (b) examining each individual narrative and coding significant text segments relevant to the research questions; (c) examining and aggregating the coded texts into categories; d) refining categories into case-specific themes (Creswell, 2007). After completing the case-by-case analysis, cross-case synthesis was used for cross-case analysis (Creswell, 2007; Stake, 1995). After revisiting the codes and themes generated for each of the four individual cases, we made comparisons across the cases to identify broader overarching themes that were present in four cases, as well as themes that were salient and specific to each individual case (Stake, 1995).

\section{Findings}

We begin our presentation of findings with a short description of each participant's academic acculturation narrative to provide contextual background. Following the narrative descriptions, we report the themes that emerged in the cross-case analysis, highlighting the academic acculturation patterns across all four cases. Throughout the findings section we employ direct quotations from the participants to best capture their authentic lived experiences (Wang, Clark, \& Scheel, 2016). All names are pseudonyms.

\section{Case Descriptions}

Kandy

At the time of the interview Kandy was enrolled in the math undergraduate program in the university. She was admitted to the program with an International English Language Testing System (IELTS) spoken score of 6 with an overall score of 6.5 out of 9. She had been in Canada for a year and a half when we spoke with her. Kandy was considered a very high-achieving student in China. For her high school English tests, she usually achieved somewhere around 135 out of 150 (90\%). In an English language education context where grades are the core focus, her teachers and parents all praised her English proficiency. Consequently, before she came to Canada, Kandy was very confident that she would be able to communicate in English, thinking to herself, “Ah, it's just speaking ABCs. How hard could it be?" She was very excited about beginning her international study before her arrival in Canada.

However, very soon after beginning her Canadian journey Kandy's excitement was replaced by shock, embarrassment, frustration, and loneliness. It suddenly dawned on her that her oral English was "worlds apart" from the English spoken by Canadians, and that she was not even speaking English but "Chinglish, " a blend of Chinese and English that was often difficult for her Canadian peers to understand. She was not able to bond with Canadians around her to make friends because she could not engage in smooth conversations. After more than a year of study, Kandy gradually started to learn to navigate her life (thanks to connections to the Chinese international student community on campus) but still found it hard to socialize with her Canadian peers and was nervous about speaking English. She explained:

\footnotetext{
For instance, I still don't know how to say "gym” correctly. Every time I talk to the Canadian students, they think I am saying "dream" instead. So, whenever I tried to say "gym," I would have to stop to think about it. They would always say, "repeat after me." I would repeat after them every time. But every time I said it differently. Even I could tell that I said it differently every time. So, I still don't know how to say "gym" correctly after more than a year in Canada. It is just frustrating, and I still cannot make real close Canadian friends.
}

Selina

At the time of her first interview, Selina had been in the university language program for about four months, which she was required to complete before she could officially start her undergraduate study. She was admitted to the program with an International English Language Testing System (IELTS) spoken score of 5.5 out of 9. Selina came to Canada for her final year of high school after studying two years in an international high school in China. Including her one year of high school study, she had been in Canada for a year and a half when we spoke with her. 
During the interview, Selina reported experiencing a number of struggles with her academic acculturation during her Canadian high school study, and so she felt happy and relieved about the conditional university admission with a year of language study to re-learn the basics of English before she actually started her undergraduate program. However, her family felt the opposite. Selina reported that her parents could not understand why she didn't have many opportunities to speak English in Canada. They could not understand that Selina was "afraid" to speak the Chinglish that constantly caused communication difficulties in her conversations with Canadians. Instead Selina's family blamed for her not working hard enough to learn and acculturate.

Being in the university language program, most of Selina's daily learning and social activities happened within the School of English, separated from other regular undergraduate students on campus. Given the fact that the majority of students in her language class were from China, Selina almost always spoke Chinese outside of class and had only Chinese friends. She expressed concerns about the language program being deficient in preparing her for her undergraduate study together with other Canadian students. She explained:

\begin{abstract}
We only have two sessions of spoken English per week, which is not much. Although I find the content regarding the sound system of English that is occasionally covered in the spoken class extremely useful, it is not enough for me to improve to a level of communication confidence ... it is not systemically taught. . . also, frankly, [with regard to the teachers in the school of English] I feel English native speakers don't really understand basic phonetic sounds very clearly . . . it is actually difficult to learn the very basics of spoken English from native speakers ... If I can't communicate in English with other Canadian students, how I am gonna make friends with them?
\end{abstract}

Nick

When we first interviewed Nick, he was enrolled in the engineering program and had been in Canada for six months. Nick completed two months of summer language coursework before he officially started his undergraduate study. He was admitted to the university with an overall IELTS score of 6 and a spoken score of 5.5.

Nick described a strong desire to socialize with other Canadian students. Even though he only interacted with his Chinese friends outside the classroom, he made it very clear that he in fact did not want to stay in the Chinese international student community, and preferred making friends with Canadians. But due to his oral English deficiency, he was not able to develop any meaningful relationships with his Canadian peers, which forced him to turn to other Chinese international students to build relationships - to feel "secure" and "connected."

When Nick was in the summer language program, he did not feel too much academic pressure even though he was nervous about speaking English in class. But once he started his undergraduate courses in the fall, he was completely overwhelmed. Since Nick came from a family that had high academic expectations, he was extremely stressed about the serious direct impact of low oral English proficiency on his grades. In describing his artifact, the artistic representation of his academic acculturation experience, a photo he took of the stairs in the library endlessly spiralling downwards, Nick explained:

\footnotetext{
When I was looking down the stairs from the top floor of the library, I felt like I was being suffocated by all the review and preview for my exams and quizzes, desperately trying to catch a breath but to no avail. For a task that took one hour for the Canadian students, I would probably need five hours. It has become well known among Chinese students that we cannot get a good grade in courses with group projects. In my geography course, Chinese students' grades are generally 20 points less than the Canadian students'.
}

Lisa

At the time of the interview, Lisa was enrolled in the Arts and Science undergraduate program and had been in Canada for four months. She was admitted to the university with an IELTS spoken score of 5.5 and a global score of 6.5. Lisa described herself as a very high achieving, socially active and influential student in her previous studies in China. Of particular note, her mother was an English teacher in China.

Similar to Kandy, Lisa was very optimistic about her English communication capacity and her international study before she came to Canada. She had a strong desire to socialize with the host culture community. Consequently, her academic acculturation process was very painful, as she felt dominated by native English speakers and excluded due to her very limited oral English 
capacity. In describing her academic acculturation, feelings of loss and inferiority featured prominently. Lisa took a picture of a barren tree as her artistic representation of her academic acculturation experiences, and explained:

\begin{abstract}
Studying here in Canada with limited spoken English makes me feel like that barren tree in the picture. Unlike the other trees around it, it has lost all its leaves. It's all barren. It's just like my life here as an international student in a Canadian universityI lost everything I had in China, my social influence, my confidence, my voice, and everything, just like that tree in the picture, barren. Nothing worked after I arrived here because of my inability to communicate, academically or socially. My inability to speak English takes my voice away in the Canadian community. When I could not say what I thought and how I felt, when I was unable to have conversations with Canadian students on an equal basis, I felt weak among them.
\end{abstract}

\title{
Cross-Case Themes
}

Four cross-case themes were evident amongst the academic acculturation experiences of the participants: (a) emotional pain, (b) involuntary isolation, (c) helplessness, and (d) regret.

\section{Emotional pain}

For all four participants, emotional pain featured prominently in their descriptions of academic acculturation. The pain resulted from the discrepancy between the participants' high expectations for their overseas study and their harsh acculturation reality. Emotionally painful feelings of "shock," "frustration," "embarrassment," "shame," "anxiety", and "inferiority" were prevalent throughout all participants' academic acculturation stories as they described encountering a variety of communication barriers. The students became anxious and nervous, because they knew they were "supposed to participate by speaking English" (Kandy), yet they were "not able to express themselves in English" (Selina). As Kandy explained, the "heart-wrenching feelings" resulting from her inability to communicate made her feel like "that person in The Scream" (Edvard Munch's famously haunting painting - Kandy's artistic representation of her acculturation experiences).

\section{Involuntary isolation}

Even though all four participants felt Canadian students were very welcoming and friendly, and desired to socialize and integrate into the host communities, they "could not bond with Canadian students" (Lisa) due to their limited oral language capacity. As a result, all of them failed to gain a sense of relatedness to the Canadian surroundings and perceived themselves as outsiders in Canada; they felt rejected by the host culture community. Eventually, after perceiving repeated rejection in their attempts to initiate conversations to develop personal relationships with Canadians, participants started to close up emotionally and gave up trying to find a place in the Canadian community. But this choice of separating from host communities on and off campus was not a personal preferred choice; it was "forced" by their inability to communicate in English. The students were separated from the host culture community and were "not living in an English-speaking environment" (Nick) despite their repeated attempts to integrate.

\section{Helplessness}

Another common theme amongst the participants' acculturation stories was helplessness. Participants experienced helplessness when they were unable to access support to relieve the psychological stress they experienced during acculturation. Although participants maintained communication with their parents and friends in China, these people were not able to provide the understanding or empathy the students needed.

Participants described trying to explain to their parents about the difficulties they were experiencing in Canada, but their parents could not empathize due to their own perceptions of their academic acculturation. Participants' parents generally held the assumption that their children's English proficiency would just quickly materialize once they started to study in an Englishspeaking country, because they perceived the English-speaking environment to be full of opportunities for them to practice English communication, unaware of the isolation their children faced. Instead of offering comfort or support, parents blamed the students for not trying to make friends with Canadians to improve their spoken English. Similarly, all participants described how their friends back in China could not offer the empathy they needed because they "had not lived the academic acculturation experience" (Kandy). 
In addition, even though psychological counselling was ostensibly available to all the students through university services, none of them chose to access it due to a worry of their inability to communicate with counsellors.

Regret

Another theme that was prominent among the students' acculturation stories was the theme of regret. Realizing how misguided and inadequate their English language preparations had been, the students felt regret. The painful acculturation experiences that resulted from their inability to communicate in English in Canada made the participants reflect on their English learning experiences back in China. This reflection awakened them to the misconceptions their parents and teachers held regarding English language learning and international education. Before their international experiences, all participants and their parents and teachers in China held the belief that, if students received the required IELTS/TOEFL score, their English was adequate for international study, and that their spoken English would improve very quickly after they came to Canada, as they imagined that they would be speaking English every day with Canadians around them. However, the participants instead experienced isolation from the host community. After realizing that test grades do not necessarily transfer to communication ability and that their minimum admission IELTS/TOEFL speaking score was "far from enough" (Nick) to get by in Canada, the participants felt deeply regretful about focusing their overseas educational preparation on test-taking skills and vocabulary and grammar rote learning, which was "useless" (Kandy) in terms of real day-to-day communication.

\section{Discussion}

The four themes of (a) emotional pain, (b) involuntary isolation, (c) helplessness, and (d) regret that emerged from our analysis clearly indicate that the participants' academic acculturation was a psychologically harsh process. When considered through the lens of Self-Determination Theory, it became apparent that the participants' low oral English proficiency severely compromised their ability to experience autonomy, competence, and relatedness, negatively impacting their psychological wellbeing during their international study in Canada.

With regard to autonomy (when one identifies one's behavior as being choiceful and self-determined), the participants clearly indicated that their lack of oral English proficiency restricted their choices. In academic settings, participants described how their limited spoken English restricted the choice of elective courses they could take, and the kind of help they could access from instructors and peers in compulsory courses. Non-academically, staying in the Chinese students' community for socializing was not a preferred choice but the only choice available to the participants as a result of their inability to socialize with Canadian students.

In addition, findings from this study confirm the positive correlation identified in the literature between oral English proficiency and international students' sense of competence (when one feels confident and capable in one's actions) (Rosenthal et al., 2006). In this study, failure to engage in both intercultural social contact and academic contact undermined participants' selfconfidence, leaving them feeling "somehow not good enough" (Lisa) compared to other Canadian students or students with sufficient oral English capacity. The self-confidence of all four participants suffered because of their low oral English proficiency, causing them to engage even less in local encounters, hindering language development and decreasing prospects of their successful academic acculturation (Sawir et al., 2012), which in turn further undermined their sense of competency.

Finally, the satisfaction of the need for relatedness, that is, belonging and connection (Deci \& Ryan, 2000), of four participants was hindered by their limited oral English communication capacity during their academic acculturation. The feeling of loneliness and isolation was prevalent. As identified by Hong, Fox, and Almarza (2007), the number of host culture friends that international students have in a new social environment is a major factor for them to acculturate successfully. However, as a direct result of the inability to engage in meaningful and smooth social conversations, none of the participants had close intercultural relationships. Although all participants reported that Canadian students were kind and sociable, initiating conversations with them and inviting them to social events at the beginning of their academic acculturation, none of the four students was able to develop meaningful intercultural relationships as their inability to speak English fluently was too inhibiting (Hayes \& Lin, 1994).

In summary, as a result of the participants' low oral English proficiency, their psychological needs of autonomy, competence and relatedness were not met, causing severe negative impact on their psychological well-being. Although a plethora of studies 
have looked at international students' academic acculturation and their overall language proficiency (Smith \& Khawaja, 2011), few researchers have focused attention to what emerged from the participant narratives in this study as the "biggest barrier" to academic acculturation - the ability to speak English. The oral component of English has profound academic and social ramifications in an English-speaking environment where native speakers are the majority and native-like English is the expectation and the norm (Derwing \& Munro, 2005).

\section{Implications}

It is significant that Chinese international students who have stayed in the host academic community for less than two years perceived the spoken component of English as the most salient stressor in their academic acculturation in this study, emphasizing the urgent need for stakeholders to proactively mitigate the negative effect of low oral language proficiency on international students' academic acculturation.

Educators who have international students in their classes should be made aware of the particular challenges new international students might face due to their insufficient ability to orally communicate. Course designs that better support acculturating international students' sense of autonomy and competence could be explored. Alternative assignment options that give acculturating international students more autonomy to choose the academic tasks that allow them to demonstrate their learning is encouraged. For example, group work and oral presentations can pose additional hurdles for participants in this study that have not acculturated successfully. As an alternative to group work, submitting an individual written report accompanied by a recorded oral presentation could significantly reduce the stress that the participants experience in English public speaking. Educators need to understand and strive to accommodate the needs of international students with limited oral communication capacity as a way to move towards education equity in the increasingly diverse post-secondary classrooms.

Additionally, in order to be truly inclusive and responsible, higher education institutions should pay particular attention to the design of support programs to better reach and include international students with low oral English proficiency on campus. Recognizing that low oral proficiency inherently creates a barrier for acculturating international students to build relation ships with the host community, student mentoring programs designed to specifically connect newly arrived international students with other successfully acculturated international students or host community members could help satisfy their need for relatedness in a foreign environment. Students services offered to acculturating international students such as social events and personal counselling could include members that are culturally and linguistically diverse. If international students bring extra revenue to host country institutions (Zhang \& Beck, 2014), budgeting for the extra support they require for success is not just a consideration but a responsibility.

Furthermore, higher education institutions should reconsider their current admission language proficiency test score requirements. The narratives from our participants signify that even with high scores in listening, reading, and writing, a low score for speaking could indicate the likelihood of severe challenges for international students to acculturate. If low oral English proficiency significantly hinders international students' success, a more stringent requirement for the spoken score should be considered instead of just focusing on the overall score of a language proficiency test (comprising listening, speaking, reading, and writing). Many higher education institutions have a lower requirement for the spoken score than reading, writing and listening. This gives a misleading message to international students regarding what they truly need to succeed in an Englishspeaking academic context.

Lastly, Chinese students and parents interested in international education need to understand the value of oral English proficiency for overseas studies and the relationship between oral communication and international students' academic acculturation. The focus of international education preparation needs to be shifted to actual authentic English communication capacities instead of admission language proficiency test score requirements. Meanwhile, Chinese English educators need to recognize that narrow test-grade-centered curricula deprive students of opportunities to truly understand the long-term goal of learning language for real-world communication and comprehend what it actually takes to prepare for an international education. 


\section{References}

Aubrey, R. (1991). International students on campus: A challenge for counselors, medical providers, and clinicians. Smith College Studies in Social Work, 62, 20-33. https://doi.org/10.1080/00377319109516697

Bagnoli, A. (2009). Beyond the standard interview: The use of graphic elicitation and arts-based methods. Qualitative Research, 9, 547-570. https://doi.org/10.1177/1468794109343625

Berry, J. W. (1997). Immigration, acculturation and adaptation. Applied Psychology: An International Review, 46, 5-34. https://doi.org/10.1111/j.1464-0597.1997.tb01087.x

Chen, C. P. (1999). Common stressors among international college students: Research and counseling implications. Journal of College Counseling, 2, 49-65. https://doi.org/10.1002/j.2161-1882.1999.tb00142.x

Chen, J. A., Liu, L., Zhao, X., \& Yeung, A. S. (2015). Chinese international students: An emerging mental health crisis. Journal of the American Academy of Child \& Adolescent Psychiatry, 54, 879-880. http://doi.org/10.1016/j.jaac.2015.06.022

Cheng, L., \& Fox, J. (2008). Towards a better understanding of academic acculturation: Second language students in Canadian universities. Canadian Modern Language Review/ La Revue Canadienne Des Langues Vivantes, 65, 307-333. http://doi.org/10.3138/cmlr.65.2.307

Creswell, J. W. (2007). Qualitative inquiry and research design: Choosing among five approaches. Sage. https://doi.org/10.1177/0011000006287390

de Charms, R. (1968). Personal causation. Academic Press. http://doi.org/10.12691/ajap-5-1-2

Deci, E. L., \& Ryan, R. M. (2000). The "what" and "why" of goal pursuits: Human needs and the self-determination of behavior. Psychological Inquiry, 11, 227-268. http://doi.org/10.1207/S15327965PLI1104 01

Deci, E. L., \& Ryan, R. M. (2002). Handbook of self-determination research. University Rochester Press.

Derwing, T., \& Munro, M. (2005). Second Language Accent and Pronunciation Teaching: A Research-Based Approach. TESOL Quarterly, 39(3), 379-397. http://doi.org/10.2307/3588486

Elliot,D., Reid, K., \& Baumfield, V. (2016). Beyond the amusement, puzzlement and challenges: An enquiry into international students' academic acculturation. Studies in Higher Education, 41(12), 2198-2217. http://doi.org/10.1080/03075079.2015.1029903

Hayes, R., \& Lin, H. R. (1994). Coming to America: Developing social support systems for international students. Journal of Multicultural Counselling and Development, 22, 7-16. https://doi.org/10.1002/j.2161-1912.1994.tb00238.x

Ho, H. J. (2017). Promoting international college students' academic adjustment from self-determination theory (Doctoral dissertation, Purdue University, West Lafayette, U.S.A.) https://docs.lib.purdue.edu/dissertations/AAI10608059/

Hong, L., Fox, R. F., \& Almarza, D. J. (2007). Strangers in stranger lands: Language, learning, and culture. International Journal of Progressive Education, 3(1), 1-44.

Ippolito, K. (2007). Promoting intercultural learning in a multicultural university: Ideas and realities. Teaching in Higher Education, 12, 749-763. https://doi.org/10.1080/13562510701596356

Leins, D. A., Fisher, R. P., Pludwinski, L., Rivard, J., \& Robertson, B. (2014). Interview protocols to facilitate human intelligence sources' recollections of meetings. Applied Cognitive Psychology, 28(6), 926-935. http://doi.org/10.1002/acp.3041

Meng, Q., Zhu, C., \& Cao, C. (2018). Chinese international students' social connectedness, social and academic adaptation: the mediating role of global competence. Higher Education, 75(1), 131-147. https://doi.org/10.1007/s10734-0170129-x

Rabionet, S. E. (2011). How I learned to design and conduct semi-structured interviews: An ongoing and continuous journey. The Qualitative Report, 16, 563-566.

Rosenthal, D. A., Russell, V. J., \& Thomson, G. D. (2006). A growing experience: The health and the well-being of international students at the University of Melbourne. Melbourne, Australia: The University of Melbourne.

Sawir, E., Marginson, S., Forbes-Mewett, H., Nyland, C., \& Ramia, G. (2012). International student security and English language proficiency. Journal of Studies in International Education, 16, 434-454. https://doi.org/10.1177/1028315311435418

Smith, R. A., \& Khawaja, N. G. (2011). A review of the acculturation experiences of international students. International Journal of Intercultural Relations, 35, 699-713. http://doi.org/10.1016/j.ijintrel.2011.08.004

Stake, R. (1995). The art of case study research. Sage.

Teixeira, J. P., Carraca, V. E., Markland, S., Silva, N. M., \& Ryan, M. R. (2012). Exercise, physical activity, and SelfDetermination Theory: A systematic review. International Journal of Behavioral Nutrition and Physical Activity, 2012 (9), 1-30. http://doi.org/10.1186/1479-5868-9-78 
Thomas, D. (2006). A general inductive approach for analyzing qualitative evaluation data. American Journal of Evaluation, 27, 237-246. https://doi.org/10.1177/1098214005283748

Wang, C. S., Clark, L. V., \& Scheel, J. M. (2016). The enculturation experience of three Chinese American adolescents: A multiple case study. The Counseling Psychologist, 44(5), 661-694. https://doi.org/10.1177/0011000016633875

White, R. W. (1959). Motivation reconsidered: The concept of competence. Psychological Review, 66, $297-333$. http://doi.org/10.1037/h0040934

Yang, R., Noels, K., \& Saumure, K. (2006). Multiple routes to cross-cultural adaptation for international students: Mapping the paths between self-construals, English language confidence, and adjustment. International Journal of Intercultural Relations, 30, 487-506. http://doi.org/10.1016/j.ijintrel.2005.11.010

Yi, L. (2004). Learning to live and study in Canada: Stories of four EFL learners from China. TESL Canada Journal, 22(1), 25-43. https://doi.org/10.18806/tesl.v22i1.164

Yin, R. K. (2003). Case study research: Design and methods. Sage Publication.

Zhang, Z., \& Beck, K. (2014). I came, but I'm lost: Learning stories of three Chinese international students in Canada. Comparative and International Education / Éducation Comparée et Internationale, 43(2), 1-14.

Zimmerman, S. (1995). Perceptions of intercultural communication competence and international student adaptation to an American campus. Communication Education, 44, 321-335. http://doi.org/10.1080/03634529509379022

\section{Please cite this article as:}

Xing, D., \& Bolden, B. (2019). Treading on a foreign land: A multiple case study of Chinese international students' academic acculturation experiences. Student Success, 10(3), 25-35. https://doi.org/10.5204/ssj.v10i3.1406

This article has been peer reviewed and accepted for publication in Student Success. Please see the Editorial Policies under the 'About' section of the Journal website for further information.

Student Success: A journal exploring the experiences of students in tertiary education

(c) () free to use with proper attribution. ISSN: 2205-0795 